\title{
Does Terminating the Avoidance of Cow's Milk Lead to Growth in Height?
}

\author{
Noriyuki Yanagida $^{a, c}$ Takanori Minoura, ${ }^{a, b}$ Setsuko Kitaoka ${ }^{a}$ \\ ${ }^{a}$ Department of Pediatrics, National Hospital Organization, Sendai Medical Center, and ${ }^{\mathrm{b}}$ Department of Pediatrics, \\ Iwakiri Hospital, Sendai, and 'Department of Pediatrics, Sagamihara National Hospital, Sagamihara, Japan
}

\section{Key Words}

Food hypersensitivity $\cdot$ Height $\cdot$ Milk $\cdot$ Growth $\cdot$ Children

\begin{abstract}
Background: Cow's milk allergy is known to result in decreased body height; accordingly, the aim of this study was to investigate whether termination of milk avoidance leads to an increase in body height. Methods: Between 2010 and 2011,253 children with food allergies who were $\geq 2$ years of age visited our outpatient department; 195 had height data available from approximately 1 year after their initial food allergy diagnosis and were included in the study. The height standard deviation scores (HtSDs) were calculated using data from the 2000 Japanese National Physical Growth Survey Report for Infants and Children, and changes in height were then retrospectively evaluated using clinical records. Results: The mean age of the 195 patients was $5.8 \pm 3.0$ years. The mean $\mathrm{HtSD}$ increased significantly from $-0.19 \pm 0.99$ at diagnosis to $-0.12 \pm 1.02(p=0.025) 1$ year later for all children. The HtSDs of 110 cases had increased, but the HtSDs of 85 cases had decreased 1 year after the initial diagnosis. The only significant factor related to increased HtSD was tolerated milk allergy 1 year after the initial diagnosis ( $p=0.004$ ). Conclusions: Terminating the avoidance of cow's milk might lead to growth in height, although a prospective study with a larger sample size is needed to confirm these results.
\end{abstract}

(C) 2015 S. Karger AG, Base

$1018-2438 / 15 / 1681-0056 \$ 39.50 / 0$

\section{Introduction}

Cow's milk allergy is the most common food allergy in children [1-4]. In an observational cohort, half the children diagnosed with a milk allergy had developed a tolerance to milk by the age of 6 years [5]. Based on an accurate diagnosis of milk allergy, avoidance of cow's milk is the only therapeutic option. Other treatment options, such as oral immunotherapy, are currently being investigated in clinical trials $[6,7]$. Oral food challenge (OFC) is usually performed to determine whether a child's allergy to cow's milk has resolved $[3,4,8]$. The avoidance of cow's milk often leads to low calcium intake [9], and thus supplementation of calcium is required for children with milk allergies. Accordingly, the World Allergy Organization has developed recommendations for feeding children who are allergic to cow's milk [10].

Several studies have reported that children who have an allergy to cow's milk are significantly shorter in height than children who do not [11-13]. Among children with food allergies, if milk or more than 2 foods are still avoided at 3 years of age, this can result in decreased growth in height by the time the children start to attend primary school [14]. In a cohort of children aged 4 years, the volume of milk consumed was associated with a status of greater weight and taller stature, while at 5 years, higher milk consumption continued to be associated with taller stature [15]. In a cohort study, daily intake of milk protein

\section{KARGER 125}

E-Mail karger@karger.com www.karger.com/iaa
Correspondence to: Dr. Noriyuki Yanagida

Department of Pediatrics, Sagamihara National Hospital 18-1 Sakuradai, Minami-ku

Sagamihara, Kanagawa 252-0392 (Japan)

E-Mail n-yanagida@ sagamihara-hosp.gr.jp 
predicted height growth [16]. However, it is not known whether terminating the avoidance of cow's milk leads to growth in height. Therefore, the aim of this study was to investigate if the reintroduction of the consumption of cow's milk in children with milk allergy resulted in height growth.

\section{Materials and Methods}

\section{Selection Criteria}

This historical cohort study of food allergies and height evaluated all patients who were $\geq 2$ years old and who visited the Sendai Medical Center between 2010 and 2011 for food allergy. This study was undertaken as part of a multicenter, prospective, observational cohort study of food allergy patients by the National Hospital Organization Allergy Network. Among these patients, we selected those with available height data at approximately 1 year (6-18 months) after the initial diagnosis. Patients' comorbid symptoms (current atopic dermatitis, bronchial asthma and allergic rhinitis) were monitored.

OFCs were performed in all patients to diagnose food allergy and to confirm the diagnosis along with tolerance of certain foods [8]. We encouraged patients who passed the 200-ml raw milk OFC to consume $200 \mathrm{ml}$ of raw milk or milk products every other day for 1 month to confirm the negative OFC results. Patients were then allowed to freely consume raw milk or milk products and were encouraged to consume milk at least twice a week. However, we advised patients with persistent milk allergy to continue to eliminate milk.

\section{Height Standard Deviation Score}

To compare patients' growth, the height standard deviation score (HtSDs) for each patient was calculated using data from the 2000 Japanese National Physical Growth Survey Report for Infants and Children, conducted by the Ministry of Health, Labour and Welfare [14]. HtSDs was calculated as (height of child - standard height)/(SD of age), and SD of age was based on data from the national survey [14]. Changes in the patients' heights were retrospectively investigated using their clinical records. For patients who had multiple data from visits and at $\geq 6$ months after their initial diagnosis, the height data that were closest to 1 year after the initial diagnosis were evaluated.

To evaluate height at approximately 1 year after initial diagnosis, patients were classified into 3 groups using the following criteria: patients with any food allergy who did not avoid cow's milk after the initial diagnosis (nonmilk food allergy group), patients who avoided cow's milk at the initial diagnosis and subsequently terminated the avoidance of cow's milk within 1 year after diagnosis (tolerated milk allergy group) and patients who continued avoiding cow's milk $>1$ year after the initial diagnosis (persistent milk allergy group).

\section{Statistical Analyses}

All results of the statistical analyses are expressed as the mean \pm SD. For intragroup comparisons, paired Student's $t$ test was used. For intergroup comparisons, the Mann-Whitney U test and Fisher's exact test were used, as appropriate. Comparisons
Table 1. Baseline clinical characteristics of 195 study participants

Males

$132(67.7)$

Age, years

$5.8 \pm 3.0$

$\mathrm{AD}$, first diagnosis

$98(50.3)$

$\mathrm{BA}$, first diagnosis

$59(30.3)$

$26(13.3)$

AR, first diagnosis

$4.5 \pm 3.7$

Number of eliminated foods 1 year after first diagnosis

$1.4 \pm 1.6$

HtSDs

$-0.19 \pm 0.99$

SD score for body weight

Data are expressed as mean $\pm \mathrm{SD}$ or $\mathrm{n}(\%) . \mathrm{AD}=$ Atopic dermatitis; $\mathrm{BA}=$ bronchial asthma; $\mathrm{AR}=$ allergic rhinitis.

between groups were conducted using analysis of variance (ANOVA) and the Bonferroni method for post hoc analyses. SPSS software (v20.0, IBM Corp., Armonk, N.Y., USA) was used for all analyses and $\mathrm{p}$ values $<0.05$ were considered statistically significant.

\section{Ethical Considerations}

According to the Declaration of Helsinki, the study design and the risks of provocation of symptoms were fully explained to the patients' guardians (verbally and in writing), and written informed consent was obtained from the guardians prior to participation. Personal details of the patients were separated from the results used in the study. Clinical data were deidentified as linked anonymized data. This study was approved by the institutional review board of the Sendai Medical Center.

\section{Results}

\section{Study Participants}

Among the 348 children with food allergies who visited our outpatient department between 2010 and 2011, 253 were $\geq 2$ years old and included in the study. On average, patients' heights were measured $258.2 \pm 165.4$ days after their initial diagnosis. At diagnosis, the mean age of the patients was $5.8 \pm 3.0$ years (range $2-16$ ), and the median age was 5.4 years (25th-75th percentile $3.6-$ 7.1). Milk allergies were found in 101 children, and 90 $(89.1 \%)$ of these children underwent an OFC (table 1). Egg allergy was found in 180 children, peanut allergy in 83 and wheat allergy in 60 . The number of eliminated foods at the time of first diagnosis was $4.5 \pm 3.7$, while the number of eliminated foods 1 year after first diagnosis was $1.4 \pm 1.6(\mathrm{p}<0.001)$. The numbers of patients who eliminated no less than 2 food items at first diagnosis and after 1 year were 118 and 34, respectively. 


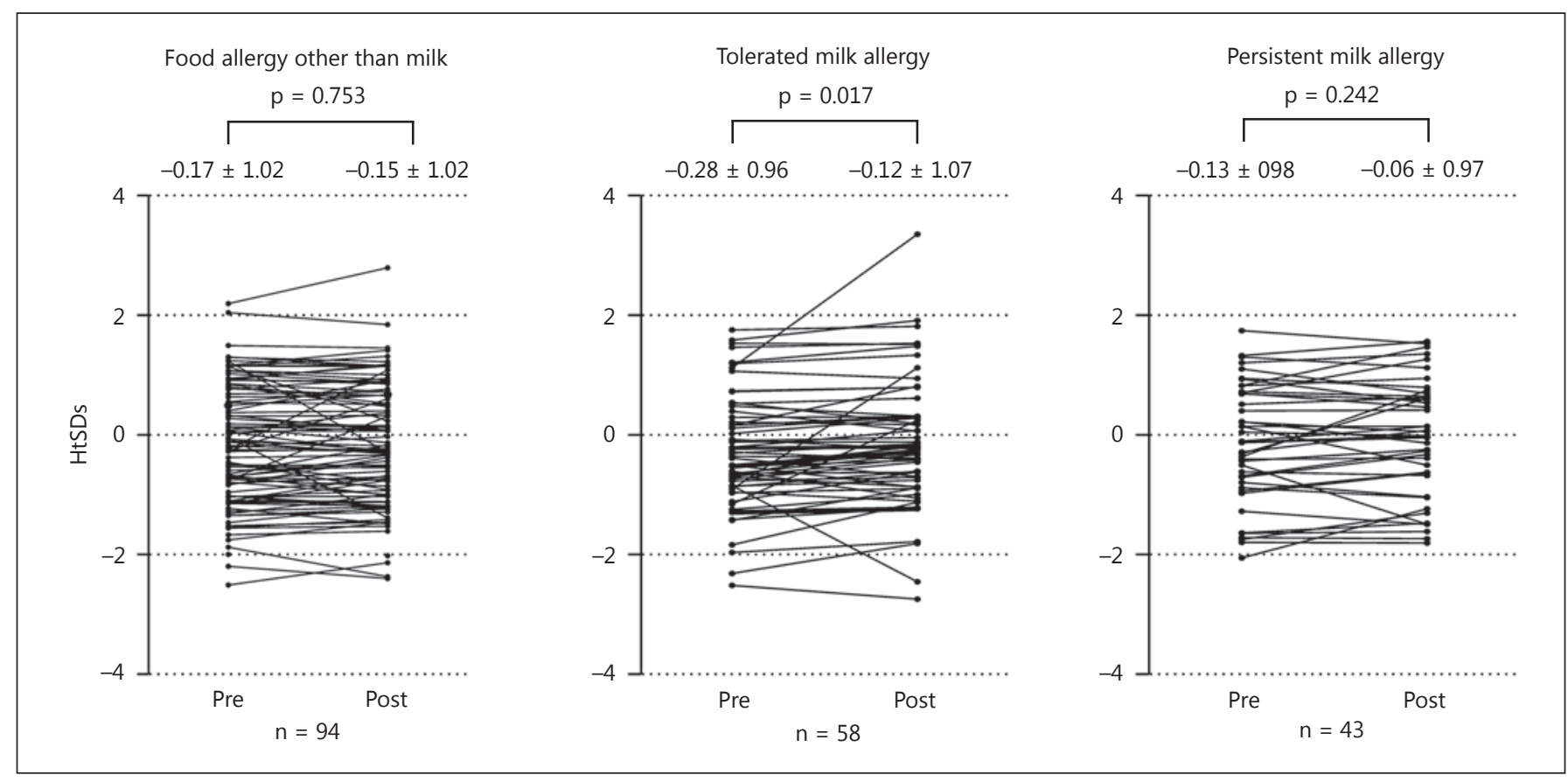

Fig. 1. HtSDs of subjects with nonmilk food allergies (left), tolerated milk allergies (center) and persistent milk allergies (right). Values (mean \pm SD) from the initial food allergy diagnosis (Pre) and from 6-18 months after the diagnosis (Post) were compared using a paired Student's t test.

Table 2. Factors related to increased HtSDs

\begin{tabular}{llll}
\hline & $\begin{array}{l}\text { Increased HtSDs } \\
(\mathrm{n}=110)\end{array}$ & $\begin{array}{l}\text { Decreased HtSDs } \\
(\mathrm{n}=85)\end{array}$ & $\mathrm{p}$ value \\
\hline Number of eliminated foods at first diagnosis & $4.8 \pm 4.0$ & $4.1 \pm 3.3$ & 0.180 \\
Number of eliminated foods 1 year after first diagnosis & $1.4 \pm 1.6$ & $1.3 \pm 1.7$ & 0.681 \\
Number of tolerated foods 1 year after first diagnosis & $3.4 \pm 3.8$ & $2.8 \pm 3.0$ & 0.216 \\
Tolerated egg allergy 1 year after first diagnosis & $74(67.3)$ & $50(58.8)$ & 0.234 \\
Tolerated milk allergy 1 year after first diagnosis & $42(38.2)$ & $16(18.8)$ & 0.004 \\
Tolerated peanut allergy 1 year after first diagnosis & $25(22.7)$ & $13(15.3)$ & 0.208 \\
Tolerated wheat allergy 1 year after first diagnosis & $33(30.0)$ & $16(18.8)$ & 0.096 \\
\hline
\end{tabular}

Data are expressed as mean \pm SD or $\mathrm{n}(\%) . \mathrm{p}<0.05$ was considered statistically significant.

\section{HtSDs Analysis}

For all patients, the HtSDs significantly increased from the time of diagnosis $(-0.19 \pm 0.99)$ to 1 year after the diagnosis $(-0.12 \pm 1.02 ; \mathrm{p}=0.025)$. The HtSDs of 110 cases increased, while those of 85 cases decreased 1 year after initial diagnosis.

The factors related to increased HtSDs, including the number of eliminated foods at first diagnosis, changes in the number of eliminated foods 1 year after first diagnosis and tolerance of egg, milk, peanut and wheat 1 year after first diagnosis, were statistically analyzed (table 2). Only acquired tolerance to milk 1 year after initial diagnosis was a significant factor related to increased HtSDs ( $\mathrm{p}=$ 0.004 ), and this remained significant after multivariate analysis using stepwise regression.

\section{HtSDs Change in the Three Groups}

The HtSDs were not significantly different among the 3 groups at initial diagnosis $(p=0.674)$. Regarding the change in HtSDs, values in the nonmilk food allergy 
group were unchanged, from $-0.17 \pm 1.02$ at diagnosis to $-0.15 \pm 1.021$ year after diagnosis $(p=0.753)$, in the tolerated milk allergy group, there was an increase from $-0.28 \pm 0.96$ at diagnosis to $-0.12 \pm 1.071$ year after diagnosis $(\mathrm{p}=0.017)$ and the values for the persistent milk allergy group were unchanged, from $-0.13 \pm 0.98$ at diagnosis to $-0.06 \pm 0.971$ year after diagnosis $(\mathrm{p}=0.242$; fig. 1). An increase in HtSD occurred in $47.9 \%$ of the nonmilk food allergy group, $72.4 \%$ of the tolerated milk allergy group and $53.5 \%$ of the persistent milk allergy group. The rates were significantly different between the tolerated milk allergy and nonmilk food allergy groups $(p=0.009)$ based on the Bonferroni post hoc analysis.

\section{Discussion}

\section{Effect of Food Elimination on Height}

Although milk allergy is known to result in decreased body height, this is the first study to report that terminating avoidance of cow's milk results in growth in height. Reducing the number of avoided foods can increase growth among children with food allergies; a previous study reported that if more than 2 foods are still avoided at 3 years of age, this can result in decreased height growth by the time the children attend primary school [14]. Nevertheless, the study did not evaluate whether body height changes when avoidance of cow's milk is terminated. In another study, multiple food allergies were reported to be associated with decreased growth of body height [1719]. This finding was not seen in our study, which may be because we evaluated more severe patients with more food eliminations than previous studies.

\section{Terminating the Avoidance of Cow's Milk Leads to}

Increased Body Height

Tolerated milk allergy 1 year after the first diagnosis was the only significant factor for increased HtSDs. Therefore, for low-body-height patients who eliminate multiple foods including milk, it may be important to consider performing an OFC for milk earlier than for other foods, in order to confirm tolerance acquisition.

Our study revealed for the first time that tolerating milk allergy leads to increased body height; however, the reason for this is currently unknown. It is known that calcium intake is an essential nutrient for physical development and growth in children $[15,20]$. Thus, we believe that the increased height of patients who developed tolerance to milk may be explained by the increase in calcium intake. Furthermore, the protein in milk, primarily the whey proteins, might contribute to increased height, as there is an association between protein-rich diets and growth [21]. However, the mechanism of this phenomenon is still unclear, and further prospective studies are therefore needed to confirm this hypothesis.

\section{Limitations}

There are several limitations in this study. First, the sample size was small. Second, as it was a retrospective examination, each subject's milk and calcium intake after terminating their avoidance of cow's milk was unclear. Therefore, further prospective studies with larger sample sizes and recording of daily calcium intake are needed to address these issues.

\section{Conclusion}

Our study suggests that in food-allergic children, terminating the avoidance of cow's milk is the most effective factor leading to growth in height. Therefore, it is important to terminate the avoidance of cow's milk as early as possible.

\section{Acknowledgements}

We thank all pediatricians and nurses who participated in recruiting the study subjects and also data collection at the Sendai Medical Center. This study was supported by funds from the National Hospital Organization.

\section{Disclosure Statement}

There are no conflicts of interests to declare.

References

Int Arch Allergy Immunol 2015;168:56-60 DOI: $10.1159 / 000441499$
1 NIAID-Sponsored Expert Panel, Boyce JA, Assa'ad A, Burks AW, Jones SM, Sampson HA, Wood RA, Plaut M, Cooper SF, Fenton MJ, Arshad SH, Bahna SL, Beck LA, ByrdBredbenner C, Camargo CA Jr, Eichenfield L, Furuta GT, Hanifin JM, Jones C, Kraft M, Levy BD, Lieberman P, Luccioli S, McCall KM, Schneider LC, Simon RA, Simons FE, Teach SJ, Yawn BP, Schwaninger JM: Guidelines for the diagnosis and management of food allergy in the United States: report of the NIAID-sponsored expert panel. J Allergy Clin Immunol 2010;126:S1-S58.

2 Lifschitz C, Szajewska H: Cow's milk allergy: evidence-based diagnosis and management for the practitioner. Eur J Pediatr 2015;174: 141-150. 
3 Burks AW, Tang M, Sicherer S, Muraro A, Eigenmann PA, Ebisawa M, Fiocchi A, Chiang W, Beyer K, Wood R, Hourihane J, Jones SM, Lack G, Sampson HA: ICON: food allergy. J Allergy Clin Immunol 2012;129:906-920.

4 Muraro A, Werfel T, Hoffmann-Sommergruber K, Roberts G, Beyer K, Bindslev-Jensen C, Cardona V, Dubois A, duToit G, Eigenmann P, Fernandez Rivas M, Halken S, Hickstein L, Høst A, Knol E, Lack G, Marchisotto MJ, Niggemann B, Nwaru BI, Papadopoulos NG, Poulsen LK, Santos AF, Skypala I, Schoepfer A, Van Ree R, Venter C, Worm M, VliegBoerstra B, Panesar S, de Silva D, SoaresWeiser K, Sheikh A, Ballmer-Weber BK, Nilsson C, de Jong NW, Akdis CA: EAACI food allergy and anaphylaxis guidelines: diagnosis and management of food allergy. Allergy 2014;69:1008-1025.

5 Wood RA, Sicherer SH, Vickery BP, Jones SM, Liu AH, Fleischer DM, Henning AK, Mayer L, Burks AW, Grishin A, Stablein D, Sampson HA: The natural history of milk allergy in an observational cohort. J Allergy Clin Immunol 2013;131:805-812.

6 Yeung JP, Kloda LA, McDevitt J, Ben-Shoshan M, Alizadehfar R: Oral immunotherapy for milk allergy. Cochrane Database Syst Rev 2012;11:CD009542.

7 Sato S, Yanagida N, Ogura K, Imai T, Utsunomiya $\mathrm{T}$, Iikura $\mathrm{K}$, Goto $\mathrm{M}$, Asaumi T, Okada Y, Koike Y, Syukuya A, Ebisawa M: Clinical studies in oral allergen-specific immunotherapy: differences among allergens. Int Arch Allergy Immunol 2014;164:1-9.
8 Yanagida N, Minoura T, Kitaoka S: Butter tolerance in children allergic to cow's milk. Allergy Asthma Immunol Res 2015;7:186-189.

9 Rockell JE, Williams SM, Taylor RW, Grant AM, Jones IE, Goulding A: Two-year changes in bone and body composition in young children with a history of prolonged milk avoidance. Osteoporos Int 2005;16:1016-1023.

10 Fiocchi A, Brozek J, Schunemann H, Bahna SL, von Berg A, Beyer K, Bozzola M, Bradsher J, Compalati E, Ebisawa M, Guzmán MA, Li H, Heine RG, Keith P, Lack G, Landi M, Martelli A, Rancé F, Sampson H, Stein A, Terracciano L, Vieths S; World Allergy Organization (WAO) Special Committee on Food Allergy: World Allergy Organization (WAO) Diagnosis and Rationale for Action against Cow's Milk Allergy (DRACMA) Guidelines. Pediatr Allergy Immunol 2010;21(suppl 21):1-125.

11 Isolauri E, Sutas $\mathrm{Y}$, Salo MK, Isosomppi R, Kaila M: Elimination diet in cow's milk allergy: risk for impaired growth in young children. J Pediatr 1998;132:1004-1009.

12 Mehta H, Ramesh M, Feuille E, Groetch M, Wang J: Growth comparison in children with and without food allergies in 2 different demographic populations. J Pediatr 2014;165: 842-848.

13 Costa LC, Rezende ER, Segundo GR: Growth parameters impairment in patients with food allergies. J Allergy (Cairo) 2014;2014:980735.

14 Mukaida K, Kusunoki T, Morimoto T, Yasumi T, Nishikomori R, Heike T, Fujii T, Nakahata T: The effect of past food avoidance due to allergic symptoms on the growth of children at school age. Allergol Int 2010;59: 369-374.
15 DeBoer MD, Agard HE, Scharf RJ: Milk intake, height and body mass index in preschool children. Arch Dis Child 2015;100:460-465.

16 Berkey CS, Colditz GA, Rockett HR, Frazier AL, Willett WC: Dairy consumption and female height growth: prospective cohort study. Cancer Epidemiol Biomarkers Prev 2009; 18: 1881-1887.

17 Sova C, Feuling MB, Baumler M, Gleason L, Tam JS, Zafra H, Goday PS: Systematic review of nutrient intake and growth in children with multiple IgE-mediated food allergies. Nutr Clin Pract 2013;28:669-675.

18 Christie L, Hine RJ, Parker JG, Burks W: Food allergies in children affect nutrient intake and growth. J Am Diet Assoc 2002;102:16481651.

19 Flammarion S, Santos C, Guimber D, Jouannic L, Thumerelle C, Gottrand F, Deschildre A: Diet and nutritional status of children with food allergies. Pediatr Allergy Immunol 2011; 22:161-165.

20 Johnston CC Jr, Miller JZ, Slemenda CW, Reister TK, Hui S, Christian JC, Peacock M: Calcium supplementation and increases in bone mineral density in children. $\mathrm{N}$ Engl J Med 1992;327:82-87.

21 Ebringer L, Ferencik M, Krajcovic J: Beneficial health effects of milk and fermented dairy products - review. Folia Microbiol (Praha) 2008;53:378-394. 